\title{
Isolation and characterization of microsatellite loci in Quercus fabri (Fagaceae)
}

\author{
Z.Z. Xiao, W.W. Chen, W. Bao, R. Wang and Y.Y. Li \\ School of Ecological and Environmental Sciences, \\ Tiantong National Station of Forest Ecosystem, \\ Shanghai Key Laboratory for Urban Ecology and Restoration, \\ East China Normal University, Shanghai, China \\ Corresponding author: Y.Y. Li \\ E-mail: yyli@des.ecnu.edu.cn
}

Genet. Mol. Res. 15 (2): gmr.15028322

Received December 21, 2015

Accepted February 11, 2016

Published June 21, 2016

DOI http://dx.doi.org/10.4238/gmr.15028322

\begin{abstract}
Quercus fabri is a pioneer species of secondary succession in evergreen broadleaved forests in China. In this study, we isolated and developed 12 polymorphic and 2 monomorphic microsatellite loci for Q. fabri using the biotin-streptavidin capture method. We characterized 12 polymorphic loci in 52 individuals from two populations. The number of alleles per locus ranged from 3 to 23 . The observed and expected heterozygosities per locus were $0.033-0.773$ and $0.138-0.924$, respectively. These microsatellite loci will facilitate the studies on genetic variation, mating system, and gene flow of $Q$. fabri.
\end{abstract}

Key words: Ecological restoration; Fagaceae; Genetic diversity; Quercus fabri; Simple sequence repeat 


\section{INTRODUCTION}

Quercus fabri Hance (Fagaceae) is a common deciduous and nut-bearing tree in subtropical forests in China. Due to its ability to grow in barren soils, high capacity to sprout, and tolerance to disturbance, $Q$. fabri is not only a pioneer species for secondary succession of evergreen broadleaved forests (EBLFs) but also plays an important role in the recovery of EBLFs, which have suffered from serious anthropogenic destructions in China and need to be restored and managed efficiently (Song and Chen, 2007). It is therefore necessary to identify the genetic variation of $Q$. fabri because a better understanding of the genetic background of early successional species will greatly contribute to the success of preliminary stages in forest recovery (Davies et al., 2015).

Microsatellites are co-dominant and highly polymorphic markers that provide an outstanding tool to detect genetic variation and have been widely used in the study of population genetics (Liu et al., 2009). In this study, 12 polymorphic and two monomorphic microsatellites in $Q$. fabri were isolated and characterized for further study of the population genetic diversity, gene flow, and parentage relationship for this species.

\section{MATERIAL AND METHODS}

Genomic DNA was extracted from silica-gel-dried leaves of one $Q$. fabri individual using the Plant Genomic DNA Extraction Kit (Tiangen, Beijing, China). This individual was collected from Tiantong, Zhejiang Province, China. Microsatellite loci were developed according to the protocol of Tong et al. (2012). A total of $250 \mathrm{ng}$ genomic DNA was digested with the MseI restriction enzyme (New England Biolabs, Beverly, MA, USA) and fragments 200-800 bp in length were produced. An MseI-adapter pair (forward: 5'-TACTCAGGACTCAT-3', reverse: 5'-GACGATGAGTCCTGAG-3') was then attached to the DNA fragments instantly and the fragments were then amplified with an MseI-N primer (5'-GATGAGTCCTGAGTAAN-3') in a $20-\mu \mathrm{L}$ reaction system using the following conditions: $95^{\circ} \mathrm{C}(3 \mathrm{~min})$, followed by 23 cycles at $94^{\circ} \mathrm{C}(30 \mathrm{~s}), 53^{\circ} \mathrm{C}(60 \mathrm{~s})$, and $72^{\circ} \mathrm{C}(60$ s). After samples were denatured at $95^{\circ} \mathrm{C}$ for $5 \mathrm{~min}$, the PCR products were hybridized with a $5^{\prime}$-biotinylated oligonucleotide probe $(\mathrm{AG})_{15} /(\mathrm{AC})_{15}$ in a $250-\mu \mathrm{L}$ solution at $48^{\circ} \mathrm{C}$ for $2 \mathrm{~h}$. The products were captured with streptavidin-coated magnetic beads (Promega Corporation, Madison, WI, USA), and then amplified with the MseI-N primer again and purified with a multifunctional DNA Extraction Kit (BioTeke, Beijing, China). Following ligation into the pMD 19-T vector (TaKaRa Biotechnology Co., Dalian, China), the products were transformed into the Escherichia coli strain JM109 by transient thermal stimulation. A total of 943 clones were tested by PCR using $(\mathrm{AG})_{10} /(\mathrm{AC})_{10}$ and $\mathrm{M}^{+} 3^{+} / \mathrm{M}^{-} 3^{-}$ as primers, respectively. Among these, 242 positive clones were chosen and sequenced on an ABI 3730 DNA Sequence Analyzer (Applied Biosystems, Foster City, CA, USA). Finally, 21 sequences were selected for use in the design of microsatellite primers with the Primer Premier 5.0 program (PREMIER Biosoft International, Palo Alto, CA, USA).

To test the performance and polymorphism for each locus, 24 Q. fabri individuals that were randomly selected from two populations in Tiantong, and Gutian, Zhejiang 
Province, China, were assessed following the method proposed by Schuelke (2000). For fluorescent labeling of PCR fragments manually, three primers were prepared: a sequencespecific forward primer with an M13(-21) tail (5'-TGTAAAACGACGGCCAGT-3') at its 5'end, a sequence-specific reverse primer, and a fluorescently (6-FAM, HEX, or ROX) labeled M13(-21) primer (Sangon Biotech, Shanghai, China). The PCR method was performed in a $15-\mu \mathrm{L}$ reaction system, including $50 \mathrm{ng}$ genomic DNA, $0.2 \mathrm{mM}$ each dNTP, $0.2 \mu \mathrm{M}$ reverse primer, $0.2 \mu \mathrm{M}$ fluorescent-labeling M13(-21) sequencing primer, $0.05 \mu \mathrm{M}$ forward primer with M13(-21) tail, 1X PCR buffer, $1.5 \mathrm{mM} \mathrm{Mg}^{2+}$, and 0.4 U DNA Taq polymerase (Sangon Biotech). The PCR amplification conditions were as follows: $94^{\circ} \mathrm{C}(5 \mathrm{~min}) ; 30$ cycles at $94^{\circ} \mathrm{C}(30 \mathrm{~s}), 56^{\circ}-63^{\circ} \mathrm{C}(45 \mathrm{~s})$ (depending on the specific locus; Table 1$)$, and $72^{\circ} \mathrm{C}(45 \mathrm{~s})$; followed by 8 cycles $94^{\circ} \mathrm{C}(30 \mathrm{~s}), 53^{\circ} \mathrm{C}(45 \mathrm{~s})$, and $72^{\circ} \mathrm{C}(45 \mathrm{~s})$; and a final extension at $72^{\circ} \mathrm{C}$ for $10 \mathrm{~min}$ on a Mastercycler ${ }^{\circledR}$ Pro thermal cycler gradient (Eppendorf, Hamburg, Germany). The PCR products were then scanned on an ABI 3730 automated sequencer (Applied Biosystems) using the internal lane standard (GS-500 LIZ) and analyzed by the GeneMapper 4.0 software (Applied Biosystems).

All polymorphic loci were further characterized in the 52 individuals collected from Tiantong and Gutian using the method proposed by Schuelke (2000). Voucher specimens were deposited at East China Normal University, China. We performed the PCR amplification for each polymorphic locus separately and scanned the products using an ABI 3730 genetic analyzer. The alleles were then binned using GeneMapper 4.0 (Applied Biosystems).

For each polymorphic locus, the number of alleles was estimated using the GENEPOP v4.0 software (Rousset, 2008). The observed $\left(H_{\mathrm{O}}\right)$ and expected $\left(H_{\mathrm{E}}\right)$ heterozygosities, HardyWeinberg equilibrium (HWE), and linkage disequilibrium were analyzed using the TFPGA version 1.3 software (Miller, 1997).

\section{RESULTS AND DISCUSSION}

We obtained clear PCR products from 14 of the 21 primer pairs tested, among which 12 loci were polymorphic and 2 loci were monomorphic (Table 1). In the 12 primer pairs tested, the number of alleles per locus varied from 3 to 23, with an average of 9.2 (Table 1). At the population level, $H_{\mathrm{O}}$ and $H_{\mathrm{E}}$ were $0.033-0.773$ and $0.138-0.924$, respectively (Table 1). No significant linkage disequilibrium $(\mathrm{P}>0.05)$ was found for any pair of loci across either population. After sequential Bonferroni adjustment (Rice, 1989), five loci (QF04, QF05, QF14, QF17, and QF20) in the Tiantong population and five loci (QF01, QF05, QF10, QF14, and QF17) in the Gutian population significantly deviated from HWE $(\mathrm{P}<0.05)$ (Table 1), most likely due to heterozygote deficiency or population structure within the samples.

We successfully developed 12 polymorphic and two monomorphic microsatellite loci for $Q$. fabri. These primers will facilitate the analysis of population genetic structure and gene flow in Q. fabri (Liu et al., 2015). The use of these markers in parentage analyses will provide key information on mating system, seed dispersal, and seedling recruitment of $Q$. fabri for a better understanding of the succession of EBLFs. 
Z.Z. Xiao et al.

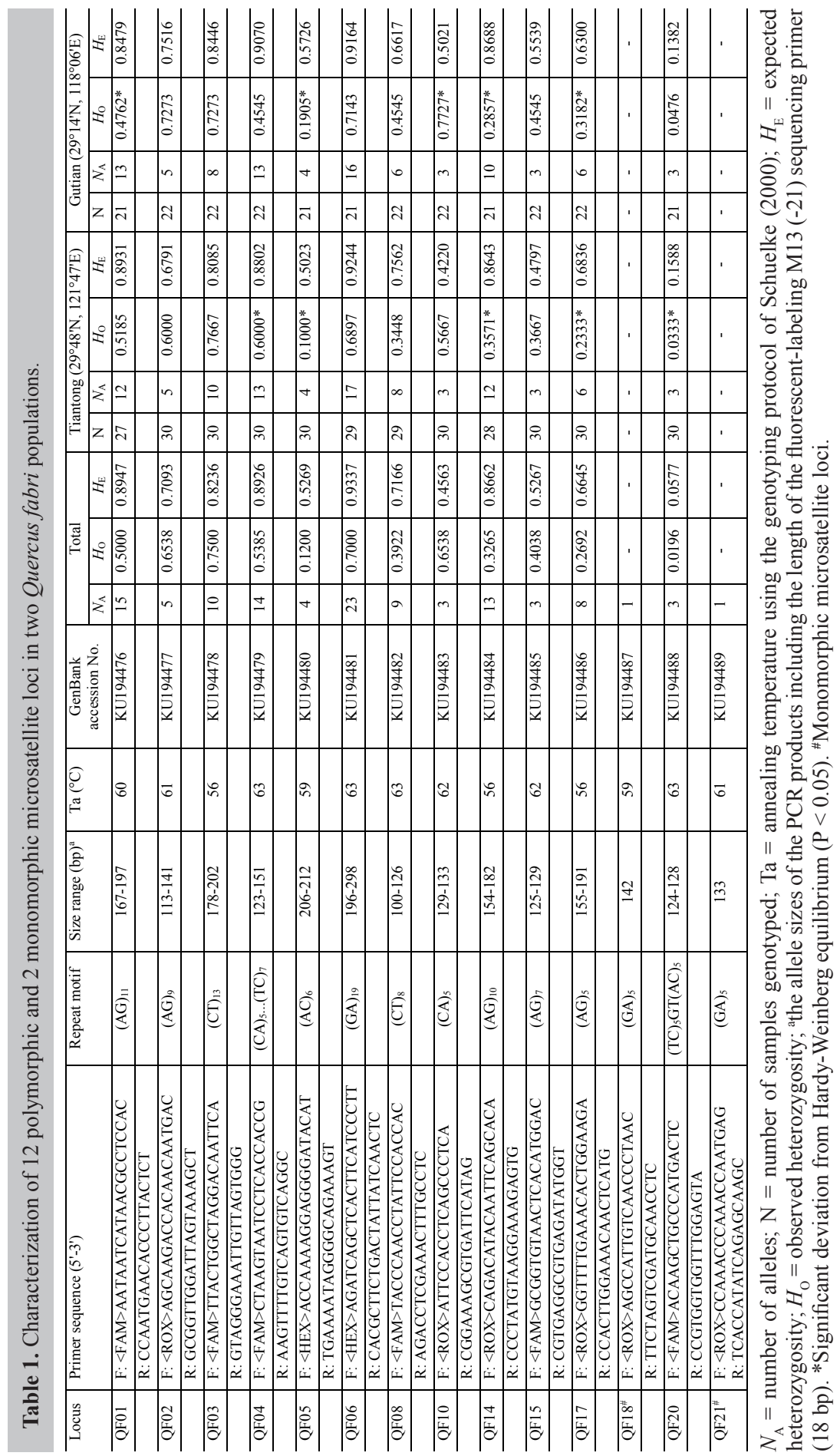




\section{Conflicts of interest}

The authors declare no conflict of interest.

\section{ACKNOWLEDGMENTS}

The authors thank Prof. X.Y. Chen for revising the manuscript, and J.H. Li, X. Tong, Q. Zhang, L.Y. Zhang, J. Gong, J.Y. Deng, and Y.Y. Ding for assistance in the field and experimental works. Research supported by the National Natural Science Foundation of China (\#31361123001) and the US National Science Foundation (Grants \#DEB-1342751 and \#DEB-1342757).

\section{REFERENCES}

Davies SJ, Cavers S, Finegan B, White A, et al. (2015). Pollen flow in fragmented landscapes maintains genetic diversity following stand-replacing disturbance in a neotropical pioneer tree, Vochysia ferruginea Mart. Heredity (Edinb) 115: 125-129. http://dx.doi.org/10.1038/hdy.2013.95

Liu M, Shi MM, Liu MH and Chen XY (2009). Isolation and characterization of microsatellite loci in Fagus longipetiolata Seem. (Fagaceae). Conserv. Genet. 10: 1981-1983. http://dx.doi.org/10.1007/s10592-009-9873-5

Liu M, Compton SG, Peng FE, Zhang J, et al. (2015). Movements of genes between populations: are pollinators more effective at transferring their own or plant genetic markers? Proc. Biol. Sci. 282: 20150290.

Miller MP (1997). Tools for population genetic analyses (TFPGA) version 1.3: a Windows program for the analysis of allozyme and molecular population genetic data. Flagstaff, AZ, Northern Arizona University.

Rice WR (1989). Analyzing tables of statistical tests. Evolution 43: 223-225. http://dx.doi.org/10.2307/2409177

Rousset F (2008). genepop'007: a complete re-implementation of the genepop software for Windows and Linux. Mol. Ecol. Resour. 8: 103-106.http://dx.doi.org/10.1111/j.1471-8286.2007.01931.x

Schuelke M (2000). An economic method for the fluorescent labeling of PCR fragments. Nat. Biotechnol. 18: 233-234. http://dx.doi.org/10.1038/72708

Song YC and Chen XY (2007). Degradation mechanism and ecological restoration of evergreen broadleaved forest ecosystem in East China. Science Press, Beijing.

Tong X, Xu NN, Li L and Chen XY (2012). Development and characterization of polymorphic microsatellite markers in Cyclobalanopsis glauca (Fagaceae). Am. J. Bot. 99: e120-e122.http://dx.doi.org/10.3732/ajb.1100448 